\title{
Doença renal policística felina: Relato de caso
}

\section{Mayara Camuri Teixeira Lopes ${ }^{1 *}$, Robson dos Anjos Honorato ${ }^{1}$, Mariela Sousa Gomes ${ }^{2}$, Esther Machado de Carvalho e Silva ${ }^{1}$, Ana Caroline Carvalho Santos ${ }^{1}$, Werner Rocha Albuquerque ${ }^{2}$}

${ }^{I}$ Residente do hospital Veterinário Universitário, Universidade Federal do Piauí

${ }^{2}$ Alunos de graduação de medicina veterinária, Universidade Federal do Piauí

*Autor para correspondencia, E-mail: mayara_camuri@hotmail.com

RESUMO. Doença renal policística (DRP) é uma doença genética que acomete frequentemente gatos persas. Os animais acometidos apresentam cistos renais.Um paciente felino da raça Persa foi atendido no Hospital Veterinário Universitário da Universidade Federal do Piauí em Teresina. No exame clínico observou-se aumento no abdômen cranial, mucosas normocoradas, desidratação $7 \%$ e temperatura retal de $37,8^{\circ} \mathrm{C}$, após o exame ultrassonográfico constatou a presença de cistos renais bilaterais.O trabalho objetivou relatar um caso de um felino da raça persa.

Palavras chaves: rim, cistos, gato persa.

\section{Policistical kidney desease - a case report}

\begin{abstract}
Polycystic kidney disease (PKD) is a genetic disease that often affects persian cats. Affected animals have renal cysts. A persian feline patient was assisted at Veterinary Universitary Hospital of Federal University of Piauí in Teresina. On clinical examination, an increase in the cranial abdomen, normocoradas mucous, $7 \%$ dehydration and rectal temperature of $37.8^{\circ} \mathrm{C}$, after the ultrasound examination revealed the presence of bilateral renal cysts. The study aimed to report a case of a persian cat breed.
\end{abstract}

Keywords: kidney, cysts, persian cat.

\section{Introdução}

Doença renal policística (PRD) é uma lesão hereditária como um traço dominante autossômico em familias de gatos persas acredita-se estar relacionada a mutações em um ou mais genes (PKD-1 e/ou PKD-2) e alteração da proteína, policistina-1 e policistina-2 (Newman, Confer \& Panciera, 2009). É uma doença genética, não ligada ao sexo, que afeta mais comumente a partir dos seis meses de idade, podendo também manifestar-se em animais com poucos dias de vida (Nunes \& Castro, 2008), acomete frequentemente gatos Persas e raças correlatas (Ondani et al., 2009). Os animais diagnosticados com essa enfermidade podem ser assintomáticos (Pinheiro et al., 2014) ou ter sinais clínicos compatíveis com insuficiência renal como poliúria, polidpsia, sensibilidade a palpação dos flancos, desidratação, anorexia e perda de peso (Santos et al., 2011).

Azotemia, hiperfosfatemia, anemia arregenerativa e acidose metabólica estão presentes em gatos predispostos ao desenvolvimento de insuficiência renal (Biller et al., 1996).

Os animais acometidos apresentam vários cistos que podem acometer córtex e medula renais, desenvolvendo-se uni ou bilateralmente, que aumentam de tamanho com a idade, levando ao comprometimento renal de caráter lento, progressivo e irreversível até a insuficiência renal (Coletti, 2006; Ondani et al., 2009).

Os cistos são geralmente esféricos, variam em tamanho, e são delineados por uma fina parede de tecido conjuntivo fibroso. São preenchidos com fluido aquoso e claro, e quando visto da superfície renal, a parede do cisto é cinza-palido, lisa e translúcida. A aparência macroscópica da superfície de corte de um rim policístico é descrito como "queijo suiço" (Newman, Confer \& Panciera, 2009).

A investigação radiográfica é inespecífica, devido à difícil diferenciação de cistos para neoplasia, sendo ultra-sonografia o exame mais 
indicado para o diagnóstico (Kealy \& Mcallister, 2005).

Scalon et al. (2014) utilizaram como método de diagnóstico a reação em cadeia da polimerase (PCR) para detectar a mutação de ponto único, utilizando dois primers específicos para o alelo mutante, no qual $9 \%$ dos gatos testados foram positivos e destes $33 \%$ eram persas.

O controle da doença é realizado pelo diagnóstico dos animais positivos antes de iniciarem a vida reprodutiva e o controle dos seu familiares com exame ultrassonográfico, além da esterilização dos animais positivos e a realização de estudos epidemiológicos sobre a prevalência da DRP em gatos da raça Persa (Colleti, 2006).

$O$ presente trabalho tem o objetivo de relatar um caso de doença renal policistica em felino da raça persa que foi atendido no Hospital Veterinário Univesitário da Universidade Federal do Piauí - UFPI.

\section{Relato do caso}

Um felino da raça Persa, fêmea, 9 anos de idade e $1,8 \mathrm{~kg}$, foi atendido no Hospital Veterinário Universitário da Universidade Federal do Piauí (HVU-UFPI).Apresentando inapetência, apatia, anorexia, poliúria, polidpsia. No exame clínico foi observado mucosas normocoradas, desidratação $7 \%$, aumento no abdômen cranial, sensibilidade a palpação do flancoe temperatura retal de $37,8^{\circ} \mathrm{C}$. O animal foi internado para estabilização do quadro geral e coletado sangue para a realização dos exames de hemograma e bioquímico. Foi encaminhado ao diagnóstico por imagem para a realização do exame ultrassonográfico.O paciente ficou internado no HVU com tratamento paliativo vindo a óbito 6 dias após a consulta. Foi solicitado ao proprietário permissão para realização da necropsia.

\section{Resultados e Discussão}

Ondani et al. (2009) conclui que a maioria dos persas diagnosticados com PKD era no mesmo criatório confirmando o caráter genético dessa doença.

$\mathrm{Na}$ ultrassonografia abdominal foram observados rins assimétricos com tamanhos aumentados, contornos irregulares e indefinidos, perda da relação córtico-medular e presença de diversas estruturas anecóicas, bem definidas e arredondadas em toda extensão do parênquima renal bilateral, sugestivo de cistos renais (Figura 1). Tais achados corroboram com os descritos por Silva et al. (2009); Santos et al. (2011) que descrevem múltiplos cistos renais bilateral. Ondani et al. (2009) relata em sua pesquisa que todos os animais positivos para PKD possuíam um ou mais cistos em ambos os rins não ocorrendo caso em apenas um rim, sendo similar a este trabalho.A DRP pode é de fácil diagnóstico através da ultrassonografia, por ser uma técnica não invasiva, que permite a precoce identificação da doença, antes de se desenvolver uma insuficiencia renal. Dessa forma a precocidade diagnóstica é de suma importancia (BILLER et al., 1996).
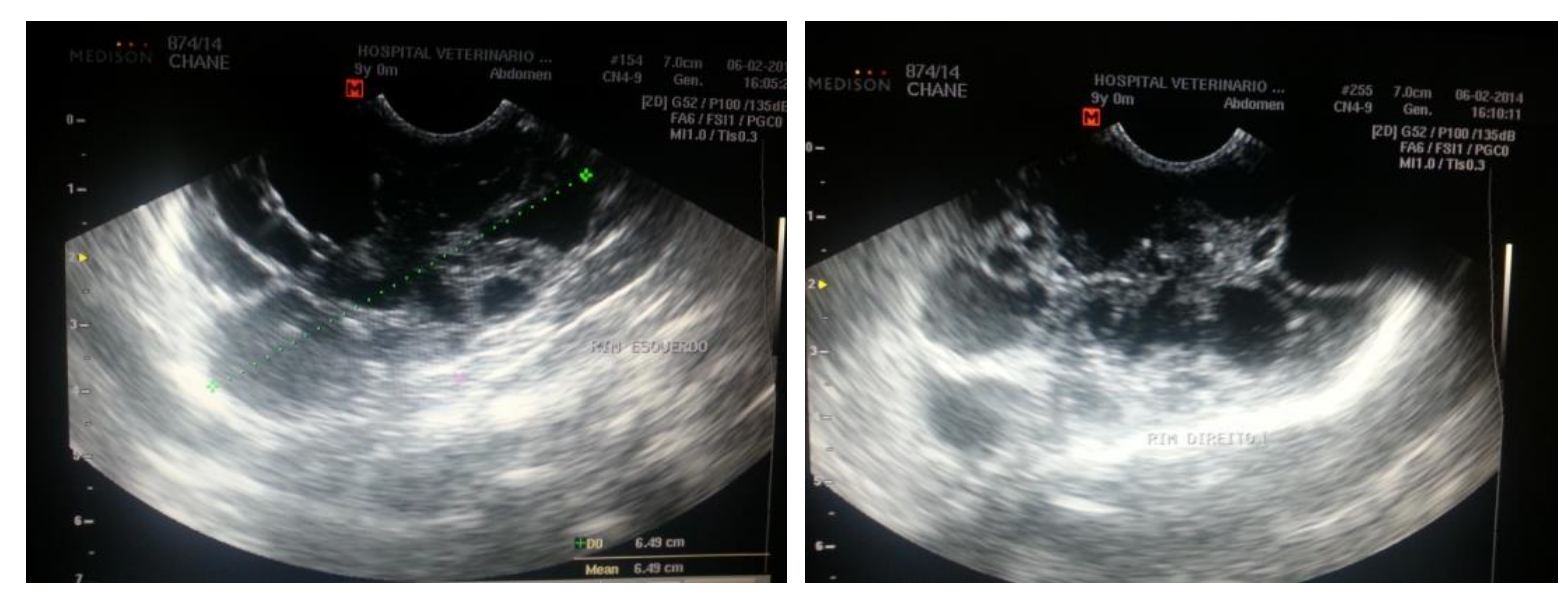

Figura 1. Imagens ultra-sonográficas de um gato persa, 9 anos com doença renal policística. A: rim esquerdo com aproximadamente $6,49 \mathrm{~cm}$ de comprimento. B: rim direito com aproximadamente 7,6 cm de comprimento. Os rins estão aumentados de volume e apresentando cistos múltiplos de tamanhos variados em toda extensão do parênquima. Foto:arquivo pessoal. 
O hemograma não revelou anemia normocítica normocrômica, trombocitopenia e linfopenia, características descritas por Silva et al. (2009) e Santos et al (2011) que relacionaram essas alterações com estado avançadode doença renal. No exame bioquímico foi constatado azotemia com valores para uréia e creatinina, respectivamente, de $381,0 \mathrm{mg} / \mathrm{dL}$ e $10,5 \mathrm{mg} / \mathrm{dL}$ (valores padrão: ureia: 10 a $60 \mathrm{mg} / \mathrm{dL}$; creatinina: $0,5$ a $1,7 \mathrm{mg} / \mathrm{dL})$, além de hiperfosfatemia (fósforo $22 \mathrm{mg} / \mathrm{dL}$ ). Não houve alterações significativas das enzimas TGP (Transaminase Glutâmica Pirúvica), fosfatase alcalina nem de proteína total e cálcio. Nelson \& Couto (2001) descrevem a presença de azotemia como sendo uma característica da fase crônica da insuficiência renal, e em relação à hiperfosfatemia, esta se relaciona como sendo resultado da excreção renal diminuída.

O tratamento, por se tratar de uma doença irreversível, é paliativo. Tem como objetivo controlar os sinais clínicos e progressão da doença, além de conservar a qualidade de vida do paciente (Silva et al., 2009). Como tratamento foi estabelecido a fluidoterapia diária que continua sendo um tratamento de eleição de animais com insuficiência renal crônica e ajuda a corrigir os distúrbios eletrolíticos e ácido-básico e uremia (Biller et al., 1996; Coletti, 2006; Silva et al., 2009). Também foi realizada uma suplementação vitamínica e mineral através da administração de complexo B, vitamina $\mathrm{C}$ e Hemolitan $\AA$, Glicopan ®. O antibioticoterapia a base de amoxicilina na dose de $12,5 \mathrm{mg} / \mathrm{kg}$-BID foi realizada devido a infecção bacteriana dos cistos ser um fator complicador em alguns gatos (Norsworthy, 2004; Coletti, 2006). O uso de analgesia opióide (Cloridrato de Tramadol) e Buscopan @ foi com finalidade de diminuição dos desconfortos abdominais advindos das alterações renais. Tendo em vista a anorexia prolongada do paciente, o mesmo foi submetido a sondagem esofágica, vindo a óbito dois dias após o procedimento.

A necrópsia confirmou a suspeita de doença renal policistica, os rins apresentavam-se aumentados de volume, com superfície irregular, consistência variando de firme a flutuante, ao corte dorsal evidenciou a presença de inúmeros cistos no córtex e medular renal de tamanhos variados com paredes finas contendo liquido aquoso e claro, resultando na destruição total do parênquima renal, achados semelhantes foram encontrados por Santos et al. (2011) e Pinheiro et al. (2014) no qual tiveram o diagnóstico da causa mortis dos animais com os achados anatomopatológicos.

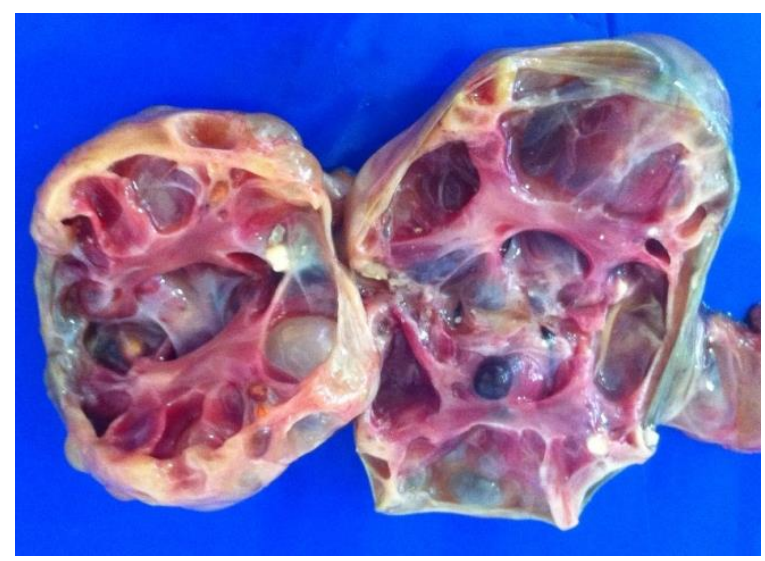

Figura 2. Imagem postmortem dos rins de um gato persa, 9 anos com doença renal policística. No corte dorsal observam-se numerosos cistos esféricos e múltiplos de tamanhos variáveis com paredes finas presentes no córtex e na medula renal. Os cistos contem fluidos claro aquoso. Foto:arquivo pessoal.

\section{Considerações finais}

Animais com doença renal policística, por ser uma doença de caráter genético, necessitam de diagnóstico precoce através principalmente de exame ultrassonográfico. Possibilitando, dessa forma, melhor qualidade de vida ao animal, uma vez que não há um tratamento específico e a ocorrência do quadro irreversível de insuficiência renal crônica trazem um prognóstico reservado a grave aos animais portadores dessa enfermidade.

\section{Referências Bibliográficas}

Biller, D.S.; Dibartola, S.P.; Eaton, K.A. et al. Inheritance of polycystic kidney disease in Persian cats. J Her, v.87, p.1-5, 1996.

Colletti, A.F. Doença renal policística felina. São Paulo: Universidade Castelo Branco, 46p. Trabalho monográfico do curso de pós graduação "Lato Sensu" em Clínica Médica de Pequenos Animais - Universidade Castelo Branco, 2006.

Nelson, R.W. \& Couto, C.G. Insuficiência Renal Crônica In: Medicina Interna de Pequenos a Animais. $2^{\mathrm{a}}$ edição. Editora Guanabara Koogan. Rio de Janeiro/RJ, 2001 p.487-499.

Newman, S. J.; Confer, A. W. \& Panciera, R. J. Sistema urinário. In: Bases da patologia em veterinária. $4^{\mathrm{a}}$ edição. Editora Elsvier. Rio de Janeiro, 2009 p. 613-691. 
Norsworthy, G. D. Doença renal policística. In: Norsworthy, G. D. et al. O Paciente Felino. 2. ed. São Paulo: Manole, 2004. Cap. 112, p. 480-3.

Nunes, L.P. \& Castro, K.F. Doença renal policística felina - Anais CONBRAVET, 2008.

Ondani, A. C. et al. Prevalência de doença renal policística em gatos domésticos da região de Jaboticabal - São Paulo - BRASIL Vet.Not., Uberlândia, v.15. n.2, jul./dez. 2009.

Pinheiro, L.L et al. Doença Renal Policistica em Felino- Relato de Caso - anais $35^{\mathrm{a}}$ Anclivepa, 2014

Santos, S.P.; Sampaio, L.C.L.; Lopes, D.J.; Sehnem, E.; Abib, S.L. \& Sampaio Jr, D.P. A. Doença renal policística em felino persa Relato de caso. 2011.

Scalon, M. C. et al. Touchdow polymerase chain reaction delection of polycystic kidney disease and laboratory findings in different cat populations. Jounal of veterinary. v. 26, p. 542-546, 2014.

Silva, M.F.O.; Drechsler, L.E.M.L.; Barros, A.M.M.; Souto, R. C.; Neves, K. R.; Silva, E.N.; Silva, F.M.F. \& Souza, M.R.Q. Doença renal policística felina: Relato de caso. 2009.

Recebido em Setembro 19, 2014

Aceito em Dezembro 4, 2014

License information: This is an open-access article distributed under the terms of the Creative Commons Attribution License, which permits unrestricted use, distribution, and reproduction in any medium, provided the original work is properly cited 